\title{
AYALA EN LA METRÓPOLIS. CIUDAD, CINE Y LITERATURA DE VANGUARDIA EN ESPAÑA A PRINCIPIOS DE SIGLO XX
}

\section{Ayala in Metropolis. City, cinema and avant-garde literature in Spain at the beginning of XXth century}

\author{
Luis D. Rivero Moreno \\ Universidad de Granada
}

Recibido: 08/04/20

Aceptado: 08/07/20

\begin{abstract}
Resumen
Esta investigación analiza el período comprendido entre finales de los ańos 20 y principios de los 30 en la literatura de Francisco Ayala. La cuestión principal gira en torno a la denominación como vanguardista de los escritos del granadino, poniéndolos en relación con otras corrientes de vanguardia españolas y europeas del momento. Ayala fue un escritor fuertemente marcado por la vivencia del cine y de la metrópolis en un momento clave de la historia contemporánea europea, un autor preocupado por el posicionamiento del artista en su contexto político y social.
\end{abstract}

\section{Palabras clave}

Francisco Ayala, cine, literatura, vanguardia, metrópolis.

\section{Abstract}

This research analyzes the period between the late 20's and early 30's in the literature of Francisco Ayala. The main issue is to solve the question about the denomination as vanguard of the writings of the Spanish writer, and after that, if possible, put them in relation to other avant-garde art currents, Spanish or European. Ayala was a writer strongly marked by the experience of cinema and the metropolis on a key moment in contemporary European history. An author concerned about the role of the artist in a particular political and social context.

\section{Key words}

Francisco Ayala, cinema, literature, avant-garde, metropolis. 


\section{Introducción}

Existen un gran número de estudios desde muy diversos puntos de vista sobre la dilatada carrera del escritor Francisco Ayala. Existen, asimismo, un buen número de obras que han querido entrar en el terreno de sus relaciones, profesionales y personales, con el cine. Este último caso ha sido enfocado, por un lado, a través del análisis de sus escritos dedicados al arte cinematográfico y a diferentes filmes y personajes fílmicos como Charlot. También se han destacado y analizado, por otro lado, los recuerdos personales del escritor en relación con el cine. La influencia de esas experiencias en su obra literaria ha sido subrayada, tengan éstas un sentido más o menos profundo o anecdótico.

Del mismo modo ha surgido en los últimos decenios una corriente de recuperación de lo que se ha denominado (tal y como lo hizo el propio Ayala) su época vanguardista (Ayala, 2006c:104). Fue ésta una época breve en que se publicaron sus compilaciones de relatos El Boxeador y un ángel (1929) (Ayala, 2006a) y Cazador en el Alba (1930) (Ayala, 2006b). Fue éste, a pesar de su corto desarrollo, un período de enorme interés y repercusión en su obra escrita a largo plazo. Una época sin duda marcada por unas circunstancias políticas y sociales extremas que terminarán por determinar para siempre el propio devenir biográfico del escritor.

Este artículo trata de revisar este período a través de las relaciones a tres bandas que se pueden construir entre la obra de aquel período en el autor granadino, el cine vanguardista de la época y su experiencia en la Berlín de fines de los años 20 y comienzos de los 30 . Con ello trataremos de trazar unas relaciones cruzadas que deben entenderse de gran complejidad y que han sido, en gran parte de los casos, tratadas de forma superficial por los estudiosos de la obra de Ayala. Éstos parecen haber asumido de modo plano la adscripción del granadino a la "vanguardia" del momento, vista de un modo general y sin entrar en sus múltiples corrientes internacionales y nacionales, en muchos casos contradictorias. Lo que sí ha sido siempre remarcado, es la apasionada relación del escritor con el cine. Tan sólo los estudios de Luis García Montero se destacan entre otros muchos que tienden a la unión y repetición de ideas manidas y nunca discutidas con un carácter crítico y debidamente contextualizado.

Lo que esta investigación trata de aclarar es si es posible denominar como propiamente vanguardista a esa etapa del escritor. Si así fuera, el siguiente paso sería ponerla en relación y/o comparación con las corrientes vanguardistas más activas y conocidas por Ayala en aquellos momentos. Para ello debemos tener en cuenta dos factores: en primer lugar, la posible influencia de los grupos locales que pudieran estar en contacto más o menos directo con el escritor. En segundo lugar, debe rastrearse el conocimiento de los movimientos y técnicas de la vanguardia europea 
que pudieran haber permeabilizado en el entorno de Ayala desde diferentes ámbitos. Todo ello teniendo en cuenta las particularidades del contexto español de la época, en el que el retraso tanto en la recepción de las corrientes vanguardistas internacionales como en el desarrollo de una vanguardia propia es evidente. Por todo ello, y como punto de partida, las posibilidades a la hora de hablar de una vanguardia española deben ser siempre matizadas. Algo que, obviamente debe ser considerado en el caso de Ayala.

En contraposición, esta investigación trata de ponderar la importancia de la vivencia berlinesa de Ayala en un momento en que, como ya hemos señalado, la cultura española aún arrastraba una considerable desconexión con los acontecimientos centroeuropeos.

También se hará un especial hincapié en las relaciones entre la vanguardia literaria y la relativa a las artes plásticas y el cine. La actitud y posición de Ayala respecto al pasado y la tradición serán claves a la hora de entender este período clave en su técnica literaria y cosmovisión del mundo. Si Ayala, como sostienen gran parte de los estudios hasta la fecha, utiliza técnicas cinematográficas en su obra, habrá que señalar qué técnicas son esas. Además, convendría señalar si realmente esas técnicas tienen relación con el cine de vanguardia del momento. También si se corresponden con una simple transposición de las mismas en su paso de la imagen cinematográfica a la palabra, y si es así, si ello las convierte automáticamente en rompedoras, avanzadas o vanguardistas.

En última instancia, ha de cuestionarse si Ayala fue realmente un personaje vanguardista. Más aún teniendo en cuenta su escaso interés en afrontar un posicionamiento abiertamente crítico frente a la tradición clásica. Esa crítica fue leitmotiv, casi cimiento fundamental y unificador de las corrientes del momento. Sin embargo, Ayala recusó este enfrentamiento y se posicionó cercano a la vanguardia atendiendo a una cierta atmósfera general del momento, como continuador de una inercia y una actitud abierta a la experimentación y la libertad temática y formal.

En todo caso y si fuera posible dictaminar vanguardismo en Ayala, deberá analizarse su posible adscripción a alguna corriente concreta o bien rastrear el uso de técnicas de una u otra. Si se admite, como hacen algunos autores, una relación a largo plazo de su obra con los objetivos de la vanguardia, se abre una vía de estudio en relación con el razonamiento de teóricos como Peter Bürger o Hal Foster. Ambos se han enfrentado a la hora de negar o admitir que el proceso iniciado por la vanguardia histórica a principios de siglo XX hubiera continuado vigente, viéndose traicionados o renovados sus objetivos durante todo ese siglo (Bürger, 1984; y Foster, 1996). Por tanto, si Ayala fue un vanguardista a lo largo de toda su trayectoria tendremos que concluir si lo fue debido a la repetición en el tiempo de lo 
planteado en aquella época, o bien lo fue en su búsqueda de una debida renovación y reactualización de aquellas originarias propuestas.

\section{Tradición y vanguardia en la España del 27}

Las relaciones entre tradición y vanguardia en la cultura española de los primeros decenios de siglo XX han sido un constante campo de batalla en la historiografía hasta nuestros días. Siendo España un país periférico y retrasado a muchos niveles, ni la revolución industrial ni la burguesa habían tenido una total repercusión en todos los territorios ibéricos aún en aquella época. Por ello, y a pesar de los continuados intentos de renovación que llegarían a su máximo exponente en los años de la II República, es necesario destacar las peculiaridades del caso español a nivel literario y artístico.

La industria cinematográfica en aquellos tiempos no había conseguido establecer una estructura profesionalizada en España. Mientras tanto la literatura y el resto de artes vivían un momento de cierto esplendor debido a la fuerte sacudida de una nueva generación de jóvenes de gran talento y energía, habitualmente agrupados en torno a generaciones. Por ello no es posible hacer relaciones equidistantes en cantidad ni calidad entre las diferentes artes. Apenas es posible hablar de propuestas vanguardistas de valor en la cinematografía española de los años 20 y 30, mientras que en literatura y artes plásticas sí pueden rastrearse artistas y movimientos de una contrastada calidad, desde el ultraísmo a ciertos focos surrealistas de considerable interés y repercusión (Gubern, 1999: 153).

De entre las generaciones, la del 27 fue una de las más destacadas, aquella que, tras los intentos previos del 98 y 14, terminó por asentar la idea de una cierta modernización que terminara por situar a España en el mapa cultural europeo. A ella se ha querido adscribir a Francisco Ayala a pesar de no corresponderse su edad a la de los componentes principales del grupo. Ayala era más joven, un hecho que el mismo autor destacaría, situándose a sí mismo como ajeno a las etiquetas generacionales (Hiriart, 1982: 49).

La lucha establecida entre la búsqueda de la necesaria renovación del país y el rescate de su tradición, sobre todo la de una rica cultura popular en peligro de extinción, será una constante fuente de debates ya desde aquellos días y se ha venido repitiendo historiográficamente hasta el momento presente. Ayala no fue ajeno a este hecho: si bien por un lado el «espíritu del momento» le llevó a abrazar las nuevas corrientes avanzadas (Hiriart, 1982: 85). Sin embargo, nunca dejó del todo de lado la utilización de un lenguaje culto ni sus referencias literarias a los clásicos del pasado, que en ningún momento trató de negar, como sí hicieran los vanguar- 
distas europeos más radicales. Su especial interés por el papel del público (Ayala, 2000) y la cultura de masas no le llevó, sin embargo, a adoptar un estilo claro y de fácil asimilación por un ciudadano medio.

La negación del pasado puede ser considerada como uno de los elementos clave de reconocimiento de toda propuesta de vanguardia. Sin embargo, es un hecho que esta negación nunca llegaría a producirse abiertamente en la cultura española del momento, ni en literatura ni en pintura o escultura. Ello nos da una idea de las características especiales de los movimientos más avanzados en la España de la época (Brihuega, 1981), difícilmente identificables como vanguardistas, o, al menos, no al cien por cien desde una óptica panorámica europea. Luis García Montero señala que en España no era viable esa ruptura tajante planteada en Europa, pues había una deuda anterior: la consolidación de un pensamiento burgués moderno (García Montero, 2006: 52-53). El primer paso era el de una modernización nunca producida. Los autores españoles, no obstante, se valdrían de ciertos aspectos de la vanguardia como herramienta con la que conseguir este objetivo primordial.

La generación del 27 se debatía entre abrazar la modernidad y no abandonar la tradición del país, su vinculación con el pueblo. Quizás ello fuera en gran parte consecuencia del aviso dado por Ortega y Gasset, uno de los pilares fundamentales de la cultura y pensamiento español del momento, y su obra La deshumanización del arte (1925) (Ortega y Gasset, 1981). En ella el filósofo advertía sobre los peligros de la separación de las corrientes vanguardistas de su conexión humana, alertando sobre la pérdida del figurativismo y todo atisbo de conexión con la realidad. Los movimientos vanguardista españoles nunca llegaron a esa ruptura abstracta, por lo que no fue necesario el retorno a un orden nunca perdido (García, 2011). Hasta tal punto ha llegado esa posición nunca radicalizada de la vanguardia española que ha sido una y otra vez puesta en duda, del mismo modo que ha sido relativizado el carácter vanguardista de la generación del 27. Incluso ha sido puesta en duda la existencia de la propia generación como tal (Anderson, 2005).

En todo caso, Ayala fue asiduo a los debates de los cafés madrileños del momento, sobre todo al dirigido por Ortega en torno a la Revista de Occidente. También se acercaría en alguna ocasión al del café de Pombo, dirigido por otro de los personajes clave de la cultura española del momento: Gómez de la Serna, al que Ayala tendría una gran admiración literaria a pesar de su falta de sintonía personal (Ayala, 2006c: 99-100). El granadino conocía los diferentes posicionamientos vanguardistas y decidió «instalarse» en ellos: «[...] sentía que la vanguardia, a cuyos movimientos extranjeros y no sólo españoles me asomé con ávida curiosidad, era la actitud idónea para dar expresión literaria a la época que estábamos viviendo» (Ayala, 2006c: 104). No obstante, su acercamiento a ella puede considerarse desde una perspectiva general y una óptica siempre personal, por lo que nunca figuró en 
la lista de ningún -ismo ni firmó manifiesto alguno. A pesar de todo, envuelto en este confuso y variado contexto, entre la tradición y el experimento (Ellis, 1984), Ayala no rehuiría la polémica y terminaría viéndose inmiscuido en algunos de los debates al respecto de la tendencia más o menos renovadora o tradicionalista de sus coetáneos. Así lo señala García Montero al destacar algunas de sus polémicas públicas con José Bergamín y Gerardo Diego (García Montero, 2009: 38-43).

España se debatía entre la largura de la sombra de la mirada al pasado, la reflexión de la anterior generación del 98 sobre la «España Negra», expuesta en las pinturas de Solana (otro habitual del café de Pombo) (Solana/Trapiello, 1998); y la repercusión que pudieran tener el dadaísmo, futurismo y surrealismo dentro de sus fronteras. Sin embargo, las más notables figuras de la vanguardia de nacionalidad española se verían obligadas al exilio (primero voluntario y luego, tras la guerra, forzado) en la búsqueda de un ambiente más propicio para sus propuestas. De ahí que la senda emprendida por Picasso la continuaran Buñuel o Dalí. El viaje, bien sin retorno o con retorno, era de obligado cumplimiento si quería conocerse el ambiente avanzado que se vivía en Centroeuropa, y, sobre todo, en París, progresivamente convertida en capital indiscutible de la vanguardia mundial. Ayala pudo experimentar este viaje, obligado Grand Tour moderno, en su estancia de estudios berlinesa de más de un año, en un viaje en que no dejaría pasar la oportunidad de una visita a la capital francesa. ¿Qué significaba para un joven vanguardista español el impacto de la experiencia europea? La constatación del retraso cultural y social de la España del momento, incluso la duda sobre el propio posicionamiento ideológico, supuestamente avanzado teniendo en cuenta el contexto español. En palabras de Ayala:

¿Se imagina acaso lo que supondría para el crudo estudiante hispano, formado -pese a sus "avanzadas" ideas - dentro de un ambiente conservador y tradicionalista, descubrir de improviso, por ejemplo, que la virginidad femenina, lejos de considerarse un galardón, podía constituir motivo de vergüenza para una muchacha [...]» (Ayala, 2006c: 155).

\section{Mito y metamorfosis}

Mito y metamorfosis serán dos palabras clave para poder entender el momento cultural vivido en España y Europa en aquella época. Por un lado, la negación del pasado era inevitable; por otro sólo era posible construir a partir de una metamorfosis, una transformación y distorsión de este mismo pasado y tradición que se negaba. Que ese proceso se hiciera de un modo más o menos violento, o que la transición fuera más fluida dependería de las circunstancias políticas de cada país 
y de las personales de cada autor. En todo caso, la metamorfosis siempre fue un elemento clave del mito, lo que nos da a entender la reutilización de conceptos como constante en la vanguardia. No se puede crear desde la nada.

Por ello, y a pesar de la sensación de tabula rasa que había en el ambiente, la recuperación de mitos clásicos sería un hecho muy habitual. No es casualidad que el surrealismo utilizara la simbología del Minotauro para uno de sus principales medios de difusión. A pesar de la violencia de la sacudida, la utilización de elementos de la mitología se sucedía, así como de las culturas y religiones llamadas primitivas y de sus ritos y formas, auténticos resortes sobre los que se impulsaron movimientos como el cubismo. La narración religiosa y mitológica se convirtió asî en toda una genealogía para el arte contemporáneo (Llauradó, 2011). Un origen de obligada visita, más aún si tenemos en cuenta que la radicalidad predicada precisaba de ir a la raíz, siguiendo su etimología.

La tecnología y la guerra habían zarandeado al hombre, sin embargo, la cultura, a pesar de su ansiada consecución de una libertad total, continuaba tratando de encontrar formas universales, de preguntarse sobre la representación, el tiempo y el espacio, tal y como se había hecho desde tiempos platónicos. La narrativa mitológica se adaptará muy bien a la nueva iconología de la ciudad, la violencia y la máquina. Los símiles se repetirán, y el viaje homérico se contrapondrá a las idas y venidas de la emigración y los medios de transporte, y a los peligros «sirénidos» de los escaparates, las luces de neón y la pantalla. Los nuevos medios y el mundo urbano serán capaces de generar imágenes de una nueva mitología que bebe directamente de la antigua, todo un imaginario del que nutrirse (Sánchez Biosca, 1998), aunque ahora al ritmo de la producción industrial.

Quizás por ello, en su reflexión sobre el cine, el nuevo y mágico medio de representación que apasionaba a las masas (Ayala, 1929a), Francisco Ayala añadió a su estudio el único poema que publicaría en toda su carrera, dedicado ni más ni menos, que a "Circe cinemática" (Ayala, 1929b). La vuelta al mito como modo de comprensión de los placeres y peligros del nuevo medio. Ayala sería consciente también de esa capacidad generadora de nuevas mitologías del cine: «Nuestro siglo se muestra pródigo en la elaboración de héroes y dioses» (Ayala, 1996: 27). Para el granadino existe una conexión clara entre la forma narrativa cinematográfica y la antigua epopeya. Por ello, el héroe moderno estará personificado en Charlot, la figura creada por Chaplin de un hombre común, atrapado por el ritmo de la ciudad y la máquina, luchador anónimo frente a la soledad, un nuevo Odiseo. Después de todo, la emigración del campo a la ciudad y la nueva vida urbana conllevará la transmutación, la transformación definitiva del hombre, tal y como es narrado por Ayala en el personaje principal de Cazador en el Alba (Vázquez Medel, 1998: 129). Una vez más la metamorfosis. 
La metamorfosis se convierte además en la base de la visión de la realidad llevada a cabo por la vanguardia. El proceso de la deformación, de la distorsión de las figuras, terminará por desembocar en el extremo de la abstracción. Las pinturas cubistas y futuristas habían adelantado este hecho: el tiempo, la velocidad de la máquina, superaba la capacidad del ojo humano de enfocar y retener las imágenes frente a él, que de este modo se fragmentan y desvanecen. El inicio de Cazador en el Alba, usando la llegada a la ciudad en el tren, es también paradigmático de esa obsesión de poesía y artes visuales por la velocidad y el aturdimiento que ésta provoca en el no iniciado. Tiempo y espacio se sitúan por entonces en pleno proceso de reconfiguración, requieren de nuevos cálculos.

En todo caso, el medio (el nuevo medio), y el proceso representativo en general, se estaba convirtiendo en sí mismo en parte fundamental del mensaje, copando las páginas de las poesías de la época. Se adelantan así las posteriores teorías de McMuhan (Mcluhan/Fiore, 1967). El cine se había convertido ya en tema recurrente y repetido en la literatura del momento.

\title{
4. El cine y la metrópolis
}

\begin{abstract}
«Estamos demasiado acostumbrados hoy día a ver en el cine revoluciones, guerras, asaltos y asonadas, todas esas espectaculares violencias, en fin, donde la bestia humana ruge; pero quien solo en el cine las haya visto, mal podrá - pienso yo-imaginarse la sencillez estupenda con que en la realidad se desenvuelven cuando por desgracia le toca a uno -como a mí, ahora- presenciarlas de veras. Transcurrido el tiempo, acontecimientos tales serán sin duda admiración de las generaciones nuevas; y el que los ha vivido pasará a sus ojos, sin otro motivo, por un héroe» (Ayala, 2014: 15)
\end{abstract}

El cine es un medio fundamental con el que entender por un lado el mundo contemporáneo y, de la misma manera, la ciudad contemporánea. Sin él no existirían ambos. El cine y la ciudad decidieron darse la mano desde el nacimiento del primero: El cine como medio completamente urbano; la ciudad convertida en metrópolis representativa. Proyecto imaginado antes que construido. Entre ambos se generó un hasta entonces desconocido modo de ver el mundo basado en la velocidad: el ritmo industrial, el movimiento de la masa, la violencia...

Sólo de ese modo podemos comprender algunas de las principales corrientes vanguardistas, por completo urbanas, entusiastas con los nuevos medios de transporte y las idas y venidas de las masas de trabajadores, las luces nocturnas de neón, el cine... en un cóctel de gran complejidad y sugerencias plásticas. Las visiones 
contradictorias llevarían de la pasión desenfrenada por lo nuevo de futurismo o constructivismo, a las visiones del reverso más oscuro de esos cambios a través del nihilismo y escepticismo expresionista o dadaista. En todo caso, nada volvería a ser lo que era en una realidad fragmentada en el tiempo, convertida en un rompecabezas espacial y temporal desde el advenimiento del cubismo, cortada y pegada en collages y assemblages.

La época de la reproductibilidad técnica (Benjamin, 2003) aspiraba a democratizar el arte asumiendo los nuevos mecanismos industrializados. Aspiraba también a acabar con el aura de la obra única para, a través de la fotografía y el cine, hacer del hombre común un hombre nuevo, consumidor de una nueva cultura a su alcance.

En este caldo de cultivo el cine era un elemento fundamental y se convirtió en todo un fenómeno de masas en pocos años. Como nos avisa Francisco Ayala: «El cine era la nueva cosa estupenda, Todas las fotografías se ponían en movimiento, y los paletos hacían un viaje a la ciudad para ver lo nunca visto» (Ayala, 1996: 13). El granadino fue además uno de los primeros escritores españoles en acercarse en su obra teórica al cine (Ayala, 1929b). Para el autor, el cine carecía de la carga del pasado del resto de artes, por lo que no recibirá el peso de las antipatías heredadas por otros medios. Si la vanguardia en las artes plásticas era elitista y de difícil digestión para el pueblo llano; el cine, en contraposición, aunaba arte y espectáculo (Ayala, 1966), era un lenguaje nuevo y universal, tan industrial y perfectamente comprensible como las cadenas en que trabajaban los obreros.

La obra de ficción de Ayala, como la de tantos otros escritores y artistas de su generación, se verá fuertemente marcada por el cine y «su acogedora oscuridad» (Morris, 1993). La propia generación del 27 ha sido vista como una generación nacida de la mano del nuevo medio, con su misma edad. Así lo afirma el propio Ayala: «Para mí como para toda mi generación el cine constituyó una experiencia fundamental; había nacido -puede decirse- con nosotros, y forma parte de nuestra vida» (Ayala, 2006c: 134). Los poemas de referencias fílmicas se sucederán en obras de muy diversos autores. La actividad de la Gaceta literaria y el Cineclub madrileño avivará los debates sobre el mismo. Tal será la influencia que los poemas empiezan a cargarse de imágenes, haciendo de lo visual el terreno principal de lo narrado (Gubern, 1999: 78).

En ese contexto encontramos a un Ayala que, a pesar de haber realizado un buen número de reseñas y otras reflexiones sobre el cine (Broullón Lozano, 2008), reconocerá que su acercamiento al mismo, como el de tantos otros de su generación, será natural y no profesional, como ávido espectador, aficionado que acude al mismo a deleitarse y no con ánimo de estudio (Ayala, 1996: 8).

«Mi afición al cine se hizo insaciable, y ha persistido a lo largo del tiempo hasta ahora. En la época a que me refiero compartía con mis compañeros de letras la admiración por el cine ruso, por el cine experimental, por las pe- 
lículas de Charlot [...], por Buster Keaton, y escribí [...] varias notículas y un ensayo que publicó la Revista de Occidente sobre algo de sociología del arte cinematográfico» (Ayala, 2006c: 134).

Ayala escribió también en aquellos años sus obras llamadas vanguardistas: $E l$ boxeador y un ángel y Cazador en el Alba. En ellas se repiten las referencias a la vida en la ciudad y al cine (Montoya, 2006). El acercamiento a este último no sólo se hará desde un punto de vista temático, sino que, tal y como han señalado muchos autores, su prosa se acercará a ciertas técnicas específicamente cinematográficas.

La vida del nuevo habitante de la ciudad se verá por completo sobrepasada por los ritmos de la ciudad y el cine. Ayala pudo experimentar dos intensos momentos vitales de enfrentamiento a la gran ciudad en sus llegadas a Madrid, primero, a principios de los años 20; y Berlín, después, ya a finales del mismo decenio.

La ciudad deslumbra, con su propia imagen panorámica y con las imágenes que la forman como mosaico interno. Del mismo modo, el cine se nutre de la luz y la velocidad en la sucesión de los fotogramas. Ayala forma parte de ese arrebato cinematográfico, de la fascinación de la vivencia en la proyección ilusoria en la pantalla. A ella se referirá en Indagación al cinema (1929). En esta obra, además de preguntarse por la dimensión social del cine, el escritor dedica gran parte de la misma a las figuras que pueblan la pantalla: Charlot, Buster Keaton, Janet Gaynor, Greta Garbo...

Ayala acierta dando esa importancia a uno de los engranajes principales de la industria: las estrellas. Éstas también aparecerán en su obra de ficción: Polar Estrella es un tragicómico relato sobre el enamoramiento que provoca el cine y sus personajes. Sin embargo, Ayala es consciente siempre del otro lado de la moneda, el desencanto de las imágenes: la desilusión que produce el choque entre realidad y ficción. El engaño de la mímesis que ese mismo año era retratado por Magritte en su serie La traición de las imágenes en una suerte de recuperación del platonismo. Polar Estrella se nos aparece como un antecedente al proceso que posteriormente y de manera igual de lúcida sería referido por Woody Allen en La Rosa Púrpura de El Cairo (The Purple Rose of Cairo, 1985). La pantalla hace vivir al entusiasmado espectador una huida de su anodina rutina urbana.

Ayala fue un gran conocedor del cine del momento, tal y como hemos señalado antes, primero por su participación en Gaceta Literaria y las proyecciones del Cineclub madrileño de la época. Después en su viaje a Berlín pudo empaparse del cine alemán de aquel tiempo (García Montero, 2006: 144), sin duda una de las industrias más poderosas y más proclive a acceder a producciones de vanguardia e interés artístico.

Las vivencias urbanas del escritor son fundamentales para entender su obra y su posición social. Su preocupación por la masa es evidente, así como por los mo- 
vimientos sociales, políticos e ideológicos que se producen en ella en ese ambiente dinámico y confuso de la ciudad. Recordemos que Ayala es sociólogo. Imagen proyectada y realidad influyen la una a la otra recíprocamente, eso bien lo sabía el granadino. Quizás por ello al hablar de su estancia en Berlín (Ingenschay, 2010), rememorada tiempo después, se refiera a ella recordando que aquel Berlín era el del poeta inglés Christopher Isherwood, y el de sus representaciones en I am a camera (Henry Cornelius, 1955) y Cabaret de Bob Fosse (1972). Y, sobre todo, era el Berlín de Grosz (García Montero, 2009: 53).

Entendemos así el conocimiento del autor no sólo de la ciudad y su atmósfera en primera persona, sino también a través de las representaciones literarias, pictóricas y cinematográficas. El Berlín que habitó Ayala, podríamos añadir, fue también el de Alfred Döblin y, por supuesto el de Metrópolis (Fritz Lang, 1927) y Berlín. Sinfonia de una ciudad (Berlin - Die Symphonie der Großstadt, Walter Ruttmann, 1927). Una megaciudad surgida casi de la nada y convertida en referencia de urbe moderna.

Ayala no dudó en señalar en aquella época las coincidencias de cine y arquitectura moderna. En ambos ve el granadino una dedicación a la colectividad (Ayala, 1996: 22). Por ello, la experiencia berlinesa debió suponer una convergencia de intereses y todo un impacto en muchos aspectos para el joven escritor, desde el punto de vista no sólo estético, sino también social. Tal y como rememora:

«Difícil sería que nadie, hoy, pueda comprender lo que para un joven español de aquel entonces significaría el encuentro con la Alemania y con la Berlín que a mí me esperaba. Era como caer de repente en otro planeta» (Ayala, 2006c: 154).

El Berlín del momento debió ser un mundo extraño, que vivía entre la prefiguración del futuro y la decadencia, entre la asepsia mecánica y la suciedad de la pobreza y los placeres terrenos. La nueva ciudad estaba plagada de contrastes a diversos niveles, del metro al rascacielos. Este último, imaginado en Metrópolis y construido en la realidad del nuevo y moderno Berlín, exponía las tensiones en todas direcciones de una sociedad dividida en la que la masa ya se debatía entre la revolución y el advenimiento del nazismo.

\section{Los fragmentos y el montaje}

La fragmentación social y la manipulación propagandística de los grandes actos en los nuevos espacios de la ciudad se entiende en este contexto y podrá ponerse en relación con la técnica vanguardista del momento. Fragmento y montaje per- 
mitirán todo tipo de narrativas al antojo de aquel que las cuenta. Y esa libertad otorgada por las nuevas técnicas vanguardistas se pondrá al servicio de los más variados y, en algunos casos, oscuros intereses. Kracauer analizó tales conexiones en su clásico estudio From Caligari to Hitler: A psychological history of the German film (1947) (Kracauer, 1947).

El cine alemán llegaba en aquellos tiempos a los picos máximos del virtuosismo narrativo y técnico: paralelamente en los filmes de Murnau y los de Leni Riefendstahl. La palabra ya no era necesaria, ni tan siquiera en intertítulos aclaratorios. El lenguaje de las imágenes había llegado al summum. Los mensajes en imágenes se imponían sobre un ciudadano convertido en autómata, un número anónimo entre la masa. Humillado (El último, Der Letzte Mann, F.W. Murnau, 1924) o enaltecido (El Triunfo de la voluntad, Triumph des Willens, Leni Riefenstahl, 1935), en todo caso el ciudadano actúa en una nueva inercia que impide su movimiento y discurrir autónomo. Lo que será aprovechado ideológicamente.

A pesar de que la influencia de cine y literatura era mutua (Hiriart, 1982: 26), la historiografía se ha decantado por la visión de que la literatura fue la damnificada, asumiendo gran parte de la técnica cinematográfica. Ciertamente la influencia social del cine era mucho mayor. La máquina de visión se había puesto a funcionar (Virilio, 1989), prefigurando la preeminencia de la imagen hasta nuestros días. La industria de la imagen cinematográfica se imponía ya en aquellos años marcando para siempre la visión del mundo y la realidad del espectador.

La técnica fragmentada y el montaje cinematográfico influirán hasta tal grado en la forma de ver el mundo que los escritores de la época comenzarán a priorizar la visión, hasta convertirse en cameraman (García Montero, 2006: 123); flaneurs que con su cámara-ojo captan la vida en la ciudad. Después de todo, el sujeto se encontraba en plena descomposición y sus pedazos podrían ser reconstruidos al antojo del cineasta. Las posibilidades demiúrgicas del montaje de imágenes parecían entonces infinitas. Dziga Vertov proclamará con entusiasmo el advenimiento de un nuevo hombre: fragmentado y reconstruido al modo de un nuevo monstruo de Frankenstein tecnológico (Vertov, 1984).

Fragmento y montaje se convierten así en herramientas básicas en la narrativa del momento (Pino, 1995). El «ojo-cámara» del escritor actuará también en el caso de Ayala, que, con tono metacinematográfico, monta imágenes de modo libre en sus supuestos relatos de vanguardia. Su relación con el cine es evidente y señalada sin tapujos por el propio escritor. La pregunta no obstante será: ¿de qué cine? ¿Es la influencia verdaderamente directa del cine de vanguardia?

Las dudas se asoman al constatar las reflexiones nada entusiastas respecto al cine vanguardista del momento, al más profundamente experimental y artístico. La crítica a L'étoile de Mer (Man Ray, 1928) como respuesta a una de las primeras 
sesiones del cineclub madrileño nos sitúa en un contexto paradójico en el que Ayala, en plena fase vanguardista muy influida por el cine, se alinea en oposición al cine más avanzado de la época, al menos desde el punto de vista puramente plástico.

Ayala, como muchos otros escritores de su generación, utilizó recursos técnicos literarios semejantes a los del travelling, el primer plano o el desenfoque. Sin embargo, la utilización de la fragmentación de influencia cinematográfica (Vázquez Medel, 1998: 18) no tendría por qué ser pues considerada desde el punto de vista vanguardista, pues todo filme se constituye del montaje de planos, escena y secuencias. En contra de ese cine experimental, Ayala afirma:

«Los ensayos de cine para minorías dan la impresión de cosa superflua, falsa, pedantesca. No llegan a satisfacer. Hacen preferible el cine de producción industrial» (Ayala, 1996: 21).

Por ello podemos decir que Ayala se posicionó del lado del cine industrial, comercial, defendió a Chaplin en el encendido debate del momento en que algunos vanguardistas consideraron su obra sentimental y burguesa. Tan sólo podemos rescatar en su obra de reflexión sobre el cine la defensa del efecto cómico del ralentí en Entr'acte (René Clair, 1924) (Ayala, 1996: 29-31).

Sus dudas respecto a la dificultad de comprensión del público del cine experimental no le obligarán a la crítica de ese otro cine vanguardista aunque destinado a un público general: del expresionismo alemán a la vanguardia rusa. En su prosa poética es posible distinguir más elementos que lo ponen en relación con técnicas o elementos vanguardistas, entre ellos la utilización metafórica de las imágenes semejante al montaje de atracciones de Eisenstein. Ayala conocía esa técnica que lleva a que la suma de las imágenes funcionen de modo conceptual, deriven en ideas u otras imágenes no explícitamente señaladas. A pesar de ello, lo vanguardista siempre fue entendido de un modo muy personal por Ayala, completamente ajeno a la defensa o adscripción de cualquier manifiesto o grupo. Si fue vanguardista lo fue de modo personal, sin modelo particular ni inmediato (Hiriart, 1982: 85).

«La fase vanguardista había sido para mí una cosa muy positiva, y está sin duda incorporada a cuanto después he escrito. Creo decir verdad si afirmo que gracias a ella me he sentido en libertad frente a la creación literaria, libre incluso de la propia estética vanguardista, y en franquía para buscar por mí mismo en cada caso y ante cada proyecto los medios de expresión que mejor le convenían. Si me he sentido libre de preceptos y modelos, ha sido en gran medida gracias a la vanguardia. Pues, como digo, la vanguardia me liberó, incluso de ella misma...» (Hiriart, 1982: 84) 
No obstante, podrían buscarse detalles que acerquen su postura a algunos aspectos de la vanguardia de la época: en ciertas afirmaciones que enaltecen la violencia y el ritmo de la ciudad moderna sí que parecerá acercarse al futurismo: «[...] las musas en las gradas de los estadios, la energía, la violencia, el esfuerzo de fábricas y puertos» (Ayala, 1996: 22). Los medios de transporte habían cambiado para siempre la visión de la realidad, incluso la escala de los elementos que la conformaban (Pino, 2004). Otros elementos, como la fijación por los escaparates o los maniquíes, se suceden poniéndose en relación con dadaísmo y surrealismo. También es posible atisbar un cierto antifeminismo, típico en algunas de las vanguardias de la época, sobre todo en la repetición de la idea de la mujer fatal de Polar Estrella; o de las mujeres mecánicas que aparecen en Cazador en el Alba, producto industrial y urbano (Vázquez Medel, 1998: 104-106). Una vez más la María de Metrópolis parece estar en el ambiente.

Otro aspecto muy vanguardista de la obra de Ayala será su marcado carácter de autorretrato (Vázquez Medel, 1998: 16-17). Tal y como afirma el escritor: «[...] uno escribe siempre sobre su propia vida. Sólo que, por pudor, la escribe en jeroglífico» (Ayala, 2006a: 10). El puzzle, el jeroglífico, la fragmentación de la obra vanguardista acerca al granadino a la visión cubista, al mismo tiempo que otorga una enorme importancia a un proceso de comunicación que no acaba en el autor, sino que es abierto por el mismo en el planteamiento de una obra abierta (Eco, 1985) que tan sólo puede activar el lector-receptor. Los textos vanguardistas tienen así un carácter de largo plazo (Vázquez Medel, 1998: 34), admiten la esencial importancia del público, de la sociedad receptora de la obra. Este hecho será clave, aún más entendiendo el interés del granadino por esta reflexión no sólo como creador sino también como sociólogo.

Por todo ello, las creaciones avanzadas de Ayala deben entenderse como lúdicas, en consonancia al carácter infantil y juguetón de todas las vanguardias. No sólo el cine y el arte, también el deporte fue otra fuente clave de la literatura española del momento (Morelli, 2000). Percibida tanto la realidad como la literatura como una construcción, los juegos del lenguaje son planteados a partir de la aceptación o transgresión de las reglas marcadas como punto de partida (Vázquez Medel, 1998: 82).

La concepción de la vanguardia en Ayala parece ser, no obstante, entendida desde una óptica general y asimilada de modo personal por el autor. En todo caso, la vanguardia fue asumida en la vida y obra de Ayala como un modo de entender la libertad, algo que, paradójicamente, le hizo libre frente a los mismos dictados de la propia vanguardia. Y la libertad fue un concepto central también en la obra ensayística del autor (Ayala, 1959). El posicionamiento de Ayala rehuyó siempre de la etiqueta, del encasillamiento. A este respecto es reseñable la significativa anécdota 
contada por el escritor sobre el día de la proclamación de la II República en España: Obligado por el ambiente de euforia generalizada y por algunos de sus amigos a colocarse una bandera tricolor en su atuendo, Ayala no resultó del todo convencido, mostrando su resistencia habitual

«[...] a embanderarme, a catalogarme, mi repugnancia a hacer alarde de unas convicciones que, como ellos bien sabían, compartía con "todo el mundo". Y tan pronto como me ví de nuevo a solas me quité el moñito» (Ayala, 2006c: 168).

Un hecho extrapolable a todos los ámbitos de su vida: biográfico y profesional.

\section{Conclusiones}

Se puede, después de todo este recorrido, dar por buena la afirmación de que Ayala fue un escritor vanguardista, al menos durante un breve período de tiempo entre finales de los años 20 y principios de los 30 . Sobre todo, porque así lo ha defendido el propio autor en multitud de escritos y entrevistas posteriores a aquella época. Algunos autores han querido ver un poso de esa fase vanguardista a largo plazo como una constante en su obra y posicionamiento intelectual. Esa permanente actualidad defendida por Carolyn Richmond debe ser puesta en duda y revisada, pues el posicionamiento en la vanguardia no es permanente por definición, requiere un adelantarse a los tiempos que impide su anquilosamiento. Para ello la reactualización debería ser constante.

No obstante, y ampliando su visión a las artes plásticas, el propio Ayala se atreverá a señalar la revisión del espíritu de la vanguardia histórica en movimientos posteriores a la II Guerra Mundial, ya en los años 60 y 70 (Hiriart, 1982: 86). Estas ideas expuestas por el granadino nos permiten actualizar su posicionamiento al respecto de las ideas de dos de los teóricos de la vanguardia más importantes de los últimos decenios: Peter Bürger y Hal Foster. Si el primero defendió el fracaso de la vanguardia histórica, constatada en el tiempo su fagocitación por parte de unas instituciones que aplacarían su carácter transgresor y violento; el segundo, en contraposición, no dudará en afirmar que lo planteado por las mismas no son más que elementos en constante revisión y reactualización por parte de las segundas $y$ venideras vanguardias, permitiendo entender su cometido como inacabado y a largo plazo.

En el confuso contexto de las vanguardias de los años 20 y 30, Ayala fue un decidido admirador del cine debido a su vitalidad de recién nacido y su falta de necesidad de hostilidad con su propia tradición. Fue un vanguardista que rechazó la 
violencia y la agresividad, fue un intelectual avanzado en un entorno aún retrasado y periférico como el español, lo que explica, si no justifica, su indiscutible lugar en la primera línea dentro de la atmósfera hispana de la época. Lo que resulta evidente es que Ayala fue un escritor español que vivió la experiencia de la metrópolis en un momento clave de la historia contemporánea europea. Y, si hay aspectos claramente vanguardistas en los escritos de Ayala, éstos tienen que ver con los ritmos sincopados, la velocidad, la fragmentación, desorientación y confusión capaz de generar el cine y la ciudad en los espectadores y habitantes de la misma a comienzos del siglo XX. El granadino fue hijo de su tiempo y, como tal, se vio en la obligación de asumir, de disfrutar y sufrir, los hitos de semejante período, en su vida y en su escritura. Como bien sabía el escritor, sólo la relectura podrá activar los textos en el futuro, prolongando su actualidad.

\section{Nota Biográfica}

Doctor en Historia del Arte (Universidad de Granada). Profesor en el Departamento de Historia del Arte de la Universidad de Granada. Licenciado en Historia del Arte (Universidad de Extremadura) y Máster en Historia del Arte: Conocimiento y Tutela del Patrimonio Histórico (Universidad de Granada). Ha realizado estancias en la Universidade Nova de Lisboa (Portugal); la Martin Luther Universität de Halle (Alemania); y la Comisión Europea, Bruselas (Bélgica).

También ha trabajado en la Biblioteca Central de La Universidad de Extremadura; el Museo Vostell de Malpartida de Cáceres y el Servicio de Archivos, Museos y Artes Plásticas de la Junta de Extremadura coordinando exposiciones y catálogos. Miembro del grupo de investigación "HUM-736. Tradición y Modernidad encla Cultura Artística Contemporánea” de la Universidad de Granada desde 2009. Ha sido colaborador en la "Revista de Cine Versión Original", y miembro del comité de redacción y secretario de la revista de investigación "HUM736. Papeles de Cultura Contemporánea”.

A todo ello se debe añadir su actividad como docente e investigador en la Universidad de Granada y su trabajo como project manager para Taso Desarrollos SL desde el que ha trabajado como investigador en el proyecto H2020 "ROCK. Regeneration and Optimisation of Cultural heritage in creative and Knowledge cities". 


\section{Bibliografía}

Anderson, A. A. 2005. El veintisiete en tela de juicio. Madrid: Gredos.

Ayala, Francisco. 1929. "El cine, musa popular”. En: Síntesis, 23: 191-197.

Ayala, Francisco. 1929. "Indagación del cinema". En: Revista de Occidente, 70: 31-42.

Ayala, Francisco. 1959. Tecnología y libertad (Vol. 12). Taurus.

Ayala, Francisco. 1966. El Cine: arte y espectáculo. Universidad Veracruzana.

Ayala, Francisco. 1996. El escritor y el cine.

Ayala, Francisco. 2000. "Para quién escribimos nosotros". En: Renacimiento, 27/30: 99-

101.

Ayala, Francisco. 2006a. El boxeador y un ángel. Biblioteca Nacional.

Ayala, Francisco. 2006b. Cazador en el alba. Editorial Renacimiento.

Ayala, Francisco. 2006c. Recuerdos y olvidos (1906-2006). Alianza editorial.

Ayala, Francisco. 2014. Muertes de perro. Alfaguara.

Benjamin, Walter. 2003. La obra de arte en la época de su reproductibilidad técnica. México: Itaca.

Brihuega, Jaime. 1981. Las vanguardias artísticas en España, 1909-1936. Madrid: Akal.

Broullón Lozano, M. A. 2008. Francisco Ayala y el cine: reflexión teórica y producción literaria, 2008.

Bürger, Peter. 1984. Theory of the Avant-garde. Manchester: University Press.

Eco, Umberto. 1985. Obra abierta. Barcelona: Ariel.

Ellis, K. 1984. "Francisco Ayala: entre la tradición y el experimento". En: Historia y crítica de la literatura española. Crítica: 574-577

Foster, Hal. 1996. The return of the real: the avant-garde at the end of the century. Mit Press.

García, Miguel Ángel. 2011. “¿Hacia una reconfiguración radical del canon? El Veintisiete y la dialéctica de la vanguardia en España”. En: Anales de la literatura española contemporánea, Vol. 36, 1: 55-80

García Montero, Luis. 2006. Francisco Ayala y el cine.

García Montero, Luis. 2009. Francisco Ayala. El escritor en su siglo.

Gubern, Román. 1999. Proyector de luna. La generación del 27 y el cine. Barcelona: Anagrama.

Solana, J. G. y Trapiello, A. 1998. La España negra. Comares.

Hiriart, R. 1982. Conversaciones con Francisco Ayala. Espasa-Calpe.

Ingenschay, D. 2010. "El Berlín de Ayala”. En: Revista de Filología Alemana: 203-216.

Kracauer, S. 1947. From Caligari to Hitler: A psychological history of the German film. Princeton: University Press.

Llauradó, J. R. 2011. Genealogías del arte contemporáneo. Madrid: Akal.

Mcluhan, Marshall. 1967. "The medium is the message". En: New York, 123: 126-128. 
Montoya, M. 2006. "El cine en los relatos vanguardistas de Francisco Ayala". En: Hispania: $751-758$.

Morelli, G. (ed.). 2000. Ludus (cine, arte y deporte en la literatura española de vanguardia).

Valencia: Pre-Textos.

Morris, C. B. 1993. La acogedora oscuridad: el cine y los escritores españoles (1920-1936). Córdoba: Filmoteca de Andalucía.

Ortega y Gasset, José. 1981. La deshumanización del arte y otros ensayos de estética. Alianza Editorial.

Pino, J. M. 1995. Montajes y fragmentos: una aproximación a la narrativa española de vanguardia. Ámsterdam-Atlanta: Rodopi.

Pino, J. M. 2004. Del tren al aeroplano: ensayos sobre la vanguardia española. Society of Spanish and Spanish-American Studies.

Sánchez Biosca, Vicente. 1998. "El cine y su imaginario en la Vanguardia española”. En: La vanguardia en España: arte y literatura, París: CRIC: 399-412.

Vázquez Medel, M. Ángel (ed.). 1995. El universo plural de Francisco Ayala. Sevilla: Alfar. Vázquez Medel, M. Ángel. 1998. Francisco Ayala y las vanguardias. Sevilla: Alfar.

Vertov, Dziga. 1984. Kino-eye: the writings of Dziga Vertov. Univ of California Press.

Virilio, Paul. 1998. La máquina de visión. Madrid: Cátedra. 